\title{
Weekly Reader and Current Events: case studies in journalistic "objectivity" run amok
}

In October 1994 a tobacco control controversy arose from an unexpected source: the fifth-grade (ages 10-11) edition of the Weekly Reader, a weekly newspaper written for, and distributed to, young school children. That month, the newspaper ran a cover story entitled "Do cigarettes have a future?"

The story caught the attention of critics because it did not mention smoking as a cause of lung cancer or heart disease but noted in detail the jobs created by tobacco companies, the income tobacco creates for farmers, and the taxes cigarette consumers provide to the government. ${ }^{1}$ The story created a controversy in the media and inspired researchers to examine whether or not the Weekly Reader was biased in its reporting of tobacco issues. The researchers concluded that, "the poor quality of the tobacco information presented in Weekly Reader... should concern those interested in tobacco prevention among youth." 2

The researchers noted that "no tobacco use" messages in Weekly Reader were noticeably less clear following the acquisition of the Weekly Reader Corporation by K-III Communications, a firm that was owned by Kohlberg Kravis Roberts \& Company, the parent company of RJR Nabisco at that time. (KKR no longer directly owns RJR stock.)

In this issue of Tobacco Control, DeJong looks at how another Weekly Reader publication, Current Events, covered tobacco control issues before and after the KKR takeover of RJR. ${ }^{3}$ Although Current Events, published for students in the fifth to tenth grades (ages 11-16 years), never generated a public controversy similar to the notoriety gained by Weekly Reader in 1994, DeJong shows that, like Weekly Reader, the coverage of tobacco issues in Current Events changed dramatically after the KKR takeover.

Many people, tobacco control advocates and others, believe that the tobacco-friendly editorial decisions made by Current Events and Weekly Reader were no accident. Certainly anyone familiar with its aggressive marketing to young people could not be too surprised to hear that RJ Reynolds had discovered an efficient way to get its message directly into elementary school classrooms.

Many people are sceptical that the Weekly Reader Corporation would actually deliberately send a pro-tobacco message to the young readers of its publications to keep its parent company, RJ Reynolds, happy. They say that not even RJR would be so heavy-handed as to get directly involved in the editorial decision-making process of the Weekly Reader magazines.

For the record, Weekly Reader vehemently denied such insinuations. In a letter responding to a state public health official who had written to the company after the October 1994 controversy, Weekly Reader vice president and editor-in-chief Sandra Maccarone said, "If Weekly Reader were the vehicle for the tobacco industry's entrée into schools would we have published 29 articles (during the past two years) that reported anti-smoking news? I think not." (Letter to Vernice Davis Anthony, Director, Michigan Department of Public Health, 23 November 1994.) In a reply to another letter of criticism, she said, "At no time does the staff feel any 'economic pressure to distort their coverage of important health issues in the interest of money."' (Letter to Dr Kenneth Warner, University of Michigan School of Public Health, 14 November 1994.)
Was Maccarone telling the truth? It may be impossible to know, but there is at least one plausible alternative $\overline{0}$ explanation for the pro-tobacco editorial content of the $\bar{\sigma}$ Weekly Reader publications. Perhaps the Weekly Reader $\frac{\bar{c}}{\bar{T}}$ editors, aware that their behaviour would be closely scruti- $\stackrel{\Phi}{\Omega}$ nised following their takeover by a tobacco company, became extra careful in providing "objective" coverage of $\vec{\bullet}$ tobacco issues. "Objectivity" was a key to Weekly Reader's defence in the wake of public criticism; several times they $\vec{\omega}$ claimed that the "Weekly Reader presents news that is "colorful but uncolored." 4

Unfortunately, striving for objectivity can lead reporters and editors, often unwittingly, to advance the tobacco 9 industry's own media strategy. When Weekly Reader 으 defensively asks "Would we have published 29 articles that reported anti-smoking news?", the relevant question becomes "What is or isn't 'anti-smoking news'?"

In practice, objective reporting often means no more $\vec{\theta}$ than interviewing opposing sides of any issue and giving both sides room in the story. On many issues such an approach, although not exactly imaginative, doesn't necessarily affect editorial content in a biased way. On tobacco issues (and most public health issues), however, the standard formula doesn't work. Interviewing tobacco company spokespersons about tobacco issues leads to some undefendable conclusions. Statements such as "nicotine isn't addictive" or "smoking doesn't cause death or disease" are demonstrably false and yet are often reported as credible statements in credible publications. Even opinions such as "tobacco issues are controversial" (another demonstrably false claim) are accepted by reporters who feel obligated to include a statement from the tobacco industry in any article they write.

Journalists who see "objectivity" and "balance" as important guiding concepts can end up unnecessarily limiting their approach to reporting a story. ${ }^{5}$ In trying to report a story objectively, they instead create a false dichotomy, and an illusion of controversy, with anti-tobacco advocates saying one thing and the tobacco $O$ industry saying another. Dr Harvey Fineberg, Dean of the Harvard School of Public Health, once noted that reporters' solicitation of statements from the tobacco industry makes as much sense as quoting a spokesperson from the Flat Earth Society whenever the space shuttle orbits the earth.

Weekly Reader's editor explained how this approach to objective reporting works in practice: "We give both sides, and say you make the right choice. And the right choice is $\mathbb{D}$ not smoking." 1 But is it objective to tell elementary school students that there are two sides to the issue of whether or not one should smoke? Would the Weekly Reader feel obligated to give both sides of the issue about illicit drug use?

Presenting "both sides" to such questions leads to the misleading impression that the answers to the questions aren't obvious. And that's exactly what the tobacco industry would like school children to think. The content of Current Events and Weekly Reader, after the RJR takeover, illustrates what DeJong calls "strategic ambiguity", the effort by the tobacco industry to keep questions and doubts about smoking issues alive.

The tobacco industry is limited in how it can participate in the debate about tobacco issues and almost never directly refutes the claims of effective health messages. The 
industry cannot credibly make direct claims such as "Cigarette smoke doesn't smell bad" or "Smoking might actually be good for you" or "Many people enjoy being exposed to second-hand smoke". Because it can't make such claims, the industry must promote ambiguous messages, such as "the need for more study" or "tolerance" or "choice".

The challenge to health advocates, then, is to educate journalists and the public about the tobacco industry's strategy of strategic ambiguity, and work with journalists to redefine objectivity and balance in reporting.

To accomplish the first goal, we need to expose the tobacco industry's strategy of raising unnecessary questions and sustaining ambiguity for as long as possible. Especially in the context of so many recent disclosures from industry sources, we need to send the message that it isn't simply that the industry is lying but that it is undertaking a careful and intentional strategy to keep debate about tobacco issues alive.

To accomplish the second objective, we need to take an active role in working with the media to improve coverage of our issues. That doesn't mean we need to convince journalists to write simply what we tell them to write, or that there is no room for disagreement between advocates and journalists. But journalists rely on us to give them the information they need to do their jobs. The information we provide needs to include a careful analysis not only of the tobacco industry's stated positions on issues but also on its underlying strategies as well. We need to redefine the working definition of journalistic objectivity and make the case that including some types of information necessarily leads journalists to implicitly accept the tobacco industry's biased framing of an issue.

We haven't yet successfully made the case that objective reporting does not have to include the rote inclusion of anything the tobacco industry says, regardless of how much it lacks credibility. Had we successfully made that case in the past, the editors of Weekly Reader and Current Events may not have felt obligated to print "both sides" of the issue in the misleading and biased ways they did.

DeJong concludes that advocates need to be watchful of industry efforts to control public access to news about tobacco. That is certainly true. But advocates need to be equally watchful of how objective journalists unwittingly participate in tobacco industry media strategies.

PHILLIP WILBUR

Advocacy Institute,

1707 L Street, NW, Suite 400

Washington, DC 20036 USA;

email:ai0003@advinst.org

1 Kurtz H. Weekly Reader puffing for tobacco? Washington Post 1995 Nov 2: $\mathrm{C} 1, \mathrm{C} 8$

2 Balbach E, Glantz S. Tobacco information in two grade school newsweeklies: A content analysis. Am $\mathcal{f}$ Public Health 1995;85:1650-3.

3 DeJong W. When the tobacco industry controls the news: KKR, RJR Nabisco, and the Weekly Reader Corporation. Tobacco Control 1996; 5:142-148.

4 Levy D. What kids read about smoking. USA Today 1995 Oct 31:D4.

5 Wallack L, Dorfman L, Jernigan D, Themba M. Media advocacy and public health: power for prevention. Newbury Park, California: Sage Publications Inc, 1993:55. 